\title{
Diagnostic practices for patients with shortness of breath and presumed obstructive airway disorders: a cross-sectional analysis
}

\author{
Ross T. Tsuyuki PharmD MSc, William Midodzi PhD, Cristina Villa-Roel MD PhD, \\ Darcy Marciniuk MD, Irvin Mayers MD, Dilini Vethanayagam MD, Michael Chan MD, \\ Brian H. Rowe MD MSc
}

\section{Abstract}

Background: Dyspnea is a common symptom that has many causes, including obstructive airway disorders. We sought to examine previous diagnosis of obstructive airway disorders and other conditions in patients receiving treatment with inhaled medications for shortness of breath in a community setting.

Methods: This cross-sectional study included consecutive patients aged 18 years and older receiving treatment for shortness of breath with inhaled medications for a minimum of 6 months. Study participants were recruited through community pharmacies in Edmonton and Saskatoon, Canada, between February 2009 and February 2012. Previous diagnosis of obstructive airway disorders by a primary care provider was assessed by patient self-report and review of health records. We conducted an assessment (as per guidelines from the American Thoracic Society and the European Respiratory Society), including pulmonary function tests; diagnoses were adjudicated by an expert physician panel ( 2 respirologists and 1 emergency physician). The agreement between diagnoses derived from pulmonary function tests and diagnoses from primary care providers was evaluated.

Results: A total of 328 patients (median age 50 yr, 57.3\% female) underwent assessment; 134 (40.9\%) of patients reported ever having a pulmonary function test performed. After adjudication, $138(42.1 \%)$ were diagnosed with asthma only, $86(26.2 \%)$ with chronic obstructive pulmonary disease only and 11 (3.4\%) with both. Some patients (93, 28.4\%) had no evidence of obstructive airway disorders and $20(6.1 \%)$ had evidence of other conditions that cause shortness of breath, such as heart failure and pulmonary hypertension. Overall, $62(18.9 \%)$ patients could not be assigned a diagnosis.

Interpretation: In a group of community-based patients with shortness of breath being treated with inhalers, less than half ever had pulmonary function tests performed, and a considerable proportion had no evidence of lung disease or other conditions. These findings highlight the need for confirmatory testing, including pulmonary function tests, before prescribing inhalers for patients with presumed obstructive airway disorders.

sthma and chronic obstructive pulmonary disease (COPD) are 2 of the 3 most likely diagnoses for obstructive airway disorders in a patient with symptoms of shortness of breath. ${ }^{1}$ In Canada, obstructive airway disorders are common ${ }^{1}$ and are associated with substantial morbidity and mortality. In Alberta, exacerbations of COPD accounted for 85330 emergency department visits during a 6 -year period. ${ }^{2,3}$ In Ontario, researchers projected that 1 in 8 individuals will have asthma by the year 2022, suggesting that obstructive airway disorders will continue to be a considerable burden on the Canadian health care system. ${ }^{1}$ Guidelines on obstructive airway disorders, including those from the Global Initiative for Chronic Obstructive Lung Disease $^{4}$ and the Global Initiative for Asthma, ${ }^{5}$ sponsored by international associations such as the American Thoracic Society, the European Respiratory Society, the Canadian
Thoracic Society, and the National Heart, Lung and Blood Institute, have recommended use of pulmonary function testing for the diagnostic workup of patients with suspected obstructive airway disorders. Despite this recommendation, evidence exists that pulmonary function tests are underused, especially in primary care settings. ${ }^{6,7}$

Authors of recent studies have expressed concern about the accuracy of diagnosis of obstructive airway disorders, including

Competing interests: See the end of the article.

This article has been peer reviewed.

Correspondence to: Ross Tsuyuki, ross.tsuyuki@ualberta.ca

CMAJ Open 2020. DOI:10.9778/cmajo.20190168 
under- and overdiagnosis of both asthma and COPD. ${ }^{8-13}$ Moreover, it has been reported that among patients receiving treatment in the emergency department for heart failure, $38 \%$ had received improper treatment with inhaled $\beta$-agonists. ${ }^{14}$ These researchers used a starting point of a "previous physician diagnosis" of obstructive airway disorders in their determination of diagnostic accuracy. Some patients, however, are not specifically informed of their diagnosis (i.e., are prescribed a "trial" of a $\beta$-agonist or other inhaled therapy), and such patients would be excluded from these studies.

The implications of poor diagnostic accuracy include patients with severe asthma not receiving optimal management for their condition, patients with COPD misclassified as having asthma and vice versa, increased risk of hospital admission, and subsequent exacerbations. Additionally, patients may be misclassified as having an obstructive airway disorder when they have other causes of dyspnea, such as heart failure or pulmonary hypertension.

Taken together, these studies give rise to concerns about the appropriateness of providing treatment with inhaled lung medications, often before a definitive diagnosis of an obstructive airway disorder. As such, we examined previous diagnosis of obstructive airway disorders and other conditions in patients who received treatment with inhaled medications for shortness of breath in a community setting. We chose to recruit participants through referral from community pharmacies to evaluate a different population from that previously studied.

\section{Methods}

\section{Study design, setting and participants}

We used a cross-sectional design, recruiting consecutive patients aged 18 years and older from community pharmacies in Edmonton and Saskatoon, Canada, between February 2009 and February 2012. There were no inclusion or exclusion criteria for the selection of pharmacists (other than their interest in participating). Some were drawn from a network of pharmacists in Edmonton and Saskatoon that had previously participated in other health services research studies.

Pharmacists considered eligible patients who had a current prescription (refilled within the past 6 months) for an inhaled medication for shortness of breath symptoms. This included $\beta$-agonists (long and short acting), anticholinergics (long and short acting), corticosteroids and combination agents. Patients were identified by either a review of their medication lists generated by each recruiting pharmacy or when patients presented for refills of their inhaled medications. Patients were excluded if they were prescribed inhaled medications for symptoms other than shortness of breath (e.g., for a cough only). Patients were also excluded if they could not communicate in English (unless someone could facilitate translation and interpretation), were pregnant, or were unable to attend the appointment for pulmonary function testing and physical examination.

\section{Study procedures}

Patients meeting the study inclusion criteria were approached by the pharmacist (in person or over the phone and using standardized scripts) to obtain verbal consent for the project office to make contact by phone. During a telephone call, trained research personnel from the Epidemiology Coordinating and Research (EPICORE) Centre based at the University of Alberta (www.epicore.ualberta.ca) informed patients about the study procedures and asked for their verbal consent to participate.

Consenting patients were invited to undergo pulmonary function tests at either the University of Alberta or the University of Saskatchewan laboratories. Patients were contacted by telephone, to a maximum of 3 times, to schedule their testing. At the testing session, a research coordinator serving as the lead researcher trainee (or designated laboratory technician) obtained written consent and collected standardized patient information on sociodemographic characteristics, clinical history and appropriate validated disease-specific measures through self-report of the COPD Assessment Test (8-item questionnaire that provides a $0-40$ score from less to more severe impact of COPD on a patient's life), the Asthma Control Questionnaire (7-point scale that provides a $0-6$ score from no impairment to maximum impairment for symptoms and rescue use in patients with asthma), functional capacity using the Medical Research Council Dyspnea Scale (5-item scale that provides a 1-5 score from none to almost complete incapacity to breathe in patients with cardiorespiratory conditions) and the New York Heart Association Functional Classification scale (4-item scale that provides a 1-4 score from no to severe limitation in physical activity in patients with heart failure). ${ }^{15-18}$ Patients were also asked to report on their knowledge of their diagnosis of asthma and COPD from their primary care provider (family physician or specialist). Case report forms are shown in Appendix 1 (available at www.cmajopen.ca/content/8/3/E605/suppl/DC1), and the COPD Assessment Test is available at www.catestonline.org.

We performed standard pulmonary function tests, as per recommendations from the European Respiratory Society ${ }^{19}$ and the American Thoracic Society. ${ }^{20}$ This included pre-post bronchodilator spirometry testing. Methacholine challenge testing, ${ }^{21}$ using the tidal breathing method, was performed in all patients who did not show evidence of obstructive airway disorders in the initial pre- and postbronchodilator spirometry. We measured lung volumes, and we excluded pulmonary restriction based on normal total lung capacity.

A blood sample for brain natriuretic peptide measurement was collected in all patients to rule out heart failure or other heart conditions as underlying entities of the shortness of breath. Complete blood work was not examined. The Canadian Cardiovascular Society has recommended a brain natriuretic peptide measurement less than $100 \mathrm{pg} / \mathrm{mL}$ as the threshold to differentiate obstructive airway disorders as a possible cause of shortness of breath. ${ }^{22}$ For pulmonary hypertension, we measured diffusing capacity, which, in combination with elevated brain natriuretic peptide, led to a presumptive diagnosis of pulmonary hypertension.

Finally, all patients gave us permission to review their medical records (e.g., to determine the specific condition for 
which inhalers were prescribed) and the results of previous diagnostic tests, including pulmonary function tests, chest radiographs, echocardiograms and methacholine challenge testing for the determination of alternative diagnoses. Trained research assistants recorded this information from the provincial electronic health record in Alberta (www.albertanetcare.ca) and the patients' primary care provider in Saskatchewan using standardized case report forms (Appendix 1).

\section{Study outcomes}

The prevalence of asthma, COPD and nonobstructive airway disorders (heart failure and other conditions) was determined as definite or probable by our physician panel (B.H.R., I.M. and D.V.) (Table 1) through standardized criteria based on international guideline recommendations. ${ }^{4,5}$ A group of 3 expert physicians (1 emergency physician [B.H.R.] and 2 respirologists [I.M. and D.V.]) reviewed and adjudicated any case that remained unclear after the methacholine challenge test. Panelists were blinded to previous diagnoses and resolved any disagreements by consensus. The agreement between diagnoses derived from pulmonary function tests and diagnoses from primary care providers was evaluated.

\section{Sample size}

The sample size for estimating a proportion with a $95 \%$ confidence interval of expected width $+/-\mathrm{d}$ around the estimate can be calculated as $n=1.96^{\wedge} 2 \times \mathrm{P}(1-\mathrm{P}) / \mathrm{d}^{\wedge} 2$, where $\mathrm{P}$ is the expected value of the proportion. With $\mathrm{d}=0.05$ and a prevalence of obstructive airway disorders of $\mathrm{P}=0.70, n=323$.

\section{Statistical analysis}

Descriptive analyses were used to report on patient characteristics and prevalence of obstructive airway disorders in shortness of breath. Analyses were performed using SPSS Version 20.0 (IBM). Percentage of baseline characteristics and patient final diagnostic outcomes are presented for categorical variables. For continuous variables, mean and standard deviation or median and interquartile range (IQR) are presented, as appropriate. The agreement between diagnoses derived from pulmonary function tests and diagnoses from primary care provider was evaluated using the $\kappa$ statistic. $\kappa$ statistics were interpreted as follows: poor $(<0.20)$, fair $(0.20-0.40)$, moderate $(0.41-0.60)$, good $(0.61-0.80)$ and excellent $(>0.80)$.

\section{Ethics approval}

Ethics approval for this study was received from the health research ethics boards at the University of Alberta and University of Saskatchewan.

\section{Results}

The participant flow chart and overall diagnostic results are outlined in Figure 1. Of the 475 eligible patients who were initially screened and consented to participate in the study, 328 completed lung function testing and provided baseline information for diagnostic evaluation. The 147 patients who were lost to follow-up mainly did not present to the pulmonary function tests laboratory.

\section{Participant characteristics}

Twenty-eight pharmacies volunteered to enrol patients using the study protocol. Major characteristics of the study population are summarized in Table 2. Most participants were women $(188,57.3 \%)$, white $(283,86.3 \%)$ and not single $(190$, $57.9 \%$ ). The median age of participants was 50 (IQR 32-64) years, $161(49.1 \%)$ had completed postsecondary education, and $182(55.5 \%)$ were current or former smokers, with a median smoking pack-year of 19 (IQR 10-31) years. Nearly all $(319,97.3 \%)$ reported at least 1 comorbid condition with a median of 4 (IQR 3-6) comorbidities per patient. The most frequent reported comorbid conditions were allergies (255, $77.7 \%)$, gastroesophageal reflux disease $(142,43.3 \%)$ and depression (104, 31.7\%). Patients reported an existing or prior history of asthma $(181 / 216,83.8 \%)$ and COPD $(34 / 216,15.7 \%)$.

The median score for the Asthma Control Questionnaire was 1.0 (IQR 0.4-1.7) among 157 of the 181 participants who self-reported being previously diagnosed with asthma; the median score for the COPD Assessment Test was 22 (IQR

Table 1: Criteria for study diagnosis of obstructive airway disorders in patients with shortness of breath

\begin{tabular}{|c|c|c|}
\hline Disease & Study diagnosis & Criteria $^{4,5}$ \\
\hline \multirow[t]{2}{*}{ Asthma } & Definite asthma & $\begin{array}{l}\text { Increase in } \mathrm{FEV}_{1}>200 \mathrm{~mL} \text { and }>12 \% \text { above prebronchodilator } \mathrm{FEV}_{1} \\
\mathrm{OR} \\
\text { Positive response to methacholine provocation test: an airway } \\
\text { hyperresponsiveness as defined by use of } \mathrm{PC}_{20}\end{array}$ \\
\hline & Probable asthma & $\begin{array}{l}\text { Diagnosis by two-thirds consensus of the expert physician panel from review } \\
\text { of examination, current respiratory symptoms and prior medical records }\end{array}$ \\
\hline \multirow[t]{2}{*}{ COPD } & Definite COPD & Postbronchodilator $\mathrm{FEV}_{1}<80 \%$ predicted together with an $\mathrm{FEV}_{1} / \mathrm{FVC}<0.70$ \\
\hline & Probable COPD & $\begin{array}{l}\text { Diagnosis by two-thirds consensus of the expert physician panel from review } \\
\text { of examination, current respiratory symptoms and prior medical records }\end{array}$ \\
\hline Non-OADs & Probable normal or with other entities & Does not fulfill criteria for definite or probable asthma or COPD diagnoses* \\
\hline
\end{tabular}




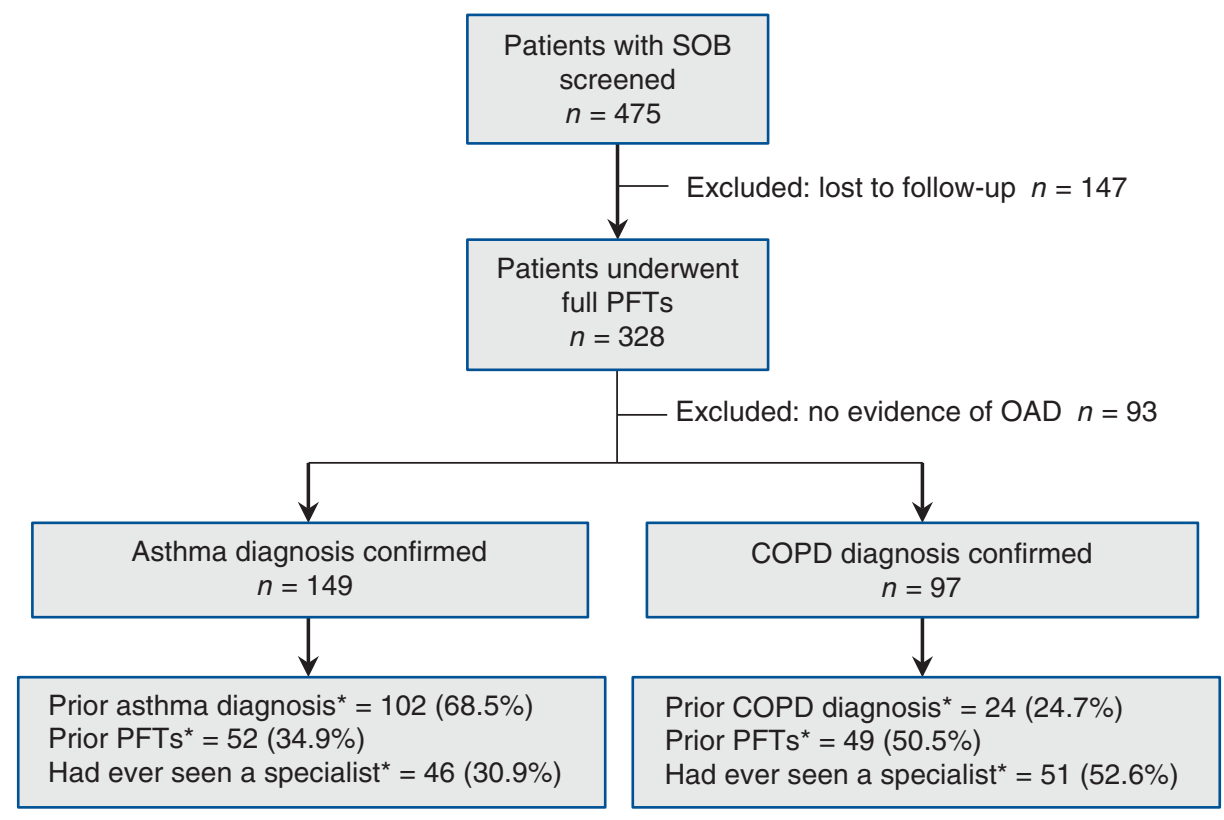

Figure 1: Flow of patients through the study. ${ }^{*}$ By patient report and medical record review. Note: COPD = chronic obstructive pulmonary disease, $\mathrm{OAD}=$ obstructive airway disorder, PFT = pulmonary function test, SOB = shortness of breath.

15-30) among 28 of the 34 who self-reported being previously diagnosed with chronic obstructive airway disease. A total of $79(24.1 \%)$ of patients reported moderate (3) to severe (5) scores on the Medical Research Council Dyspnea Scale, and $86(26.2 \%)$ reported New York Heart Association Functional Classification Scale III or IV symptoms. Current symptoms most often reported were day- or nighttime cough (29.9\%), fatigue $(21.3 \%)$, chest tightness (19.5\%) and wheezing $(19.5 \%)$, and sputum production $(17.1 \%)$.

A total of 216 patients $(65.8 \%)$ reported ever receiving a diagnosis for their shortness of breath symptoms by their primary care provider, of which $83.8 \%$ were diagnosed with asthma and $15.7 \%$ with COPD. A total of $39.0 \%$ of patients reported seeing a specialist for their shortness of breath symptoms, and $40.8 \%$ had previously had pulmonary function tests conducted (Table 2). Most of the patients previously diagnosed with asthma and COPD reported using quick-reliever medication (short-acting $\beta$-agonists) and inhaled combination agents (inhaled corticosteroids-long-acting $\beta$-agonists) in the last 6 months (Table 3).

\section{Diagnoses}

Table 4 shows the participant diagnoses derived from pulmonary function testing, using the criteria outlined in Table 1 and adjudicated by the expert physician panel. Information on previous diagnostic tests (e.g., chest radiographs, echocardiograms, methacholine challenge testing and pulmonary function tests) was available for 275 patients $(83.8 \%$ of the study population).
Asthma was confirmed in 149 patients (45.4\%) and COPD in 97 patients $(29.6 \%)$. Of the patients who had a prior diagnosis of asthma or COPD from their primary care provider, $54.9 \%$ of diagnoses were confirmed for asthma and $71.1 \%$ for COPD by adjudicated diagnosis derived from pulmonary function tests (the positive predictive values and negative predictive values are shown in Table 5). Some patients (93; $28.4 \%$ of the study sample) had no evidence of obstructive airway diseases either by spirometry data or with further methacholine challenge testing.

Of those patients diagnosed with asthma or COPD by our expert physician panel, 11 had both conditions (asthmaCOPD overlap syndrome). Confirmatory diagnosis was elusive in 62 patients $(18.9 \%$ of the study sample). An additional 8 of the 62 participants could have been classified as having Global Initiative for Chronic Obstructive Lung Disease stage 1 COPD, but we elected to include them in the group of participants with indeterminate cause for shortness of breath. Most of these participants (5/8) had forced expiratory volume in 1 second greater than $95 \%$ predicted normal, and, after review, we believed that they did not have clinically significant airflow obstruction.

In Table 5, the $\kappa$ statistics indicate there was only a poor agreement between previous diagnoses by primary care providers and by our expert physician panel $(\kappa=0.22$ for asthma; $\kappa=0.28$ for COPD). Heart failure and restrictive lung disease were the 2 most common other diagnoses determined for a patient without obstructive airway disorders. Diagnoses could not be determined by our expert 
Table 2: Characteristics of patients with shortness of breath referred by pharmacists

\begin{tabular}{|c|c|}
\hline Characteristic & $\begin{array}{c}\text { No. }(\%) \text { of } \\
\text { patients* } \\
n=328\end{array}$ \\
\hline Age, yr, median (IQR) & $50(32-64)$ \\
\hline Weight, kg, mean \pm SD & $83.3 \pm 20.7$ \\
\hline Height, $\mathrm{cm}$, mean $\pm \mathrm{SD}$ & $166.4 \pm 9.6$ \\
\hline Sex, female & $188(57.3)$ \\
\hline \multicolumn{2}{|l|}{ Ethnicity } \\
\hline White & $283(86.3)$ \\
\hline South Asian & $19(5.8)$ \\
\hline Aboriginal & $12(3.6)$ \\
\hline Other† & $14(4.3)$ \\
\hline \multicolumn{2}{|l|}{ Highest level of education } \\
\hline Completed postsecondary education & $161(49.1)$ \\
\hline Some postsecondary education & $62(18.9)$ \\
\hline High school diploma & $61(18.6)$ \\
\hline Less than grade 12 & $44(13.4)$ \\
\hline Married or common-law status & $190(57.9)$ \\
\hline \multicolumn{2}{|l|}{ Most common comorbidities } \\
\hline Allergies & $255(77.7)$ \\
\hline GERD & $142(43.3)$ \\
\hline Depression & $104(31.7)$ \\
\hline Sinus or nasal polyps & $103(31.4)$ \\
\hline Anxiety & $88(26.8)$ \\
\hline \multicolumn{2}{|l|}{ Other relevant comorbidities } \\
\hline Hypertension & $85(25.9)$ \\
\hline Anemia & $42(12.8)$ \\
\hline Coronary artery disease & $28(8.5)$ \\
\hline Heart failure & $6(1.8)$ \\
\hline \multicolumn{2}{|l|}{ Smoking history } \\
\hline Current & $65(19.8)$ \\
\hline Former & $117(35.7)$ \\
\hline Never & $146(44.5)$ \\
\hline $\begin{array}{l}\text { Pack-years for current or former smokers, } \\
\text { median (IQR) }\end{array}$ & $19(10-31)$ \\
\hline \multicolumn{2}{|l|}{ Symptoms } \\
\hline Cough symptoms (day or night) & $98(29.9)$ \\
\hline Sputum production & $56(17.1)$ \\
\hline Chest tightness & $64(19.5)$ \\
\hline Wheeze & $64(19.5)$ \\
\hline \multicolumn{2}{|l|}{ Other symptoms } \\
\hline Peripheral edema & $31(9.5)$ \\
\hline Fatigue & $70(21.3)$ \\
\hline Bilateral ankle edema & $34(10.4)$ \\
\hline Fever or flu-like symptoms & $18(5.5)$ \\
\hline Currently absent from work or school & $23(7.0)$ \\
\hline $\begin{array}{l}\text { Previously diagnosed by a primary care } \\
\text { provider for SOB symptoms }\end{array}$ & $216(65.8)$ \\
\hline Asthma & $181 / 216(83.8)$ \\
\hline COPD & $34 / 216(15.7)$ \\
\hline Other & $113 / 216(52.3)$ \\
\hline Previously seen by a specialist for SOB & $128(39.0)$ \\
\hline Previously had PFTs conducted for SOB & $134(40.8)$ \\
\hline \multicolumn{2}{|c|}{$\begin{array}{l}\text { Note: } \mathrm{COPD}=\text { chronic obstructive pulmonary disease, } \mathrm{GERD}= \\
\text { gastroesophageal reflux disease, IQR }=\text { interquartile range, } \mathrm{PFT}=\text { pulmonary } \\
\text { function test, } \mathrm{SD}=\text { standard deviation, } \mathrm{SOB}=\text { shortness of breath. } \\
\text { *Unless stated otherwise. } \\
\text { †ncluded black, Hispanic, East and Southeast Asian, Middle Eastern and other } \\
\text { ethnicities not stated in the case report form. }\end{array}$} \\
\hline
\end{tabular}

physician panel for 62 patients (18.9\% of the study sample) after pulmonary function testing and evaluation of information available in patients' medical records.

Of the 149 patients diagnosed with asthma by our expert physician panel, $34.9 \%$ reported ever having a pulmonary function test performed, whereas for the 97 patients diagnosed with COPD, $50.5 \%$ reported ever having a pulmonary function test performed (Figure 1).

\section{Interpretation}

In our study of community-dwelling patients who received treatment with inhalers for shortness of breath symptoms and referred by pharmacists, a considerable proportion did not meet the diagnostic criteria for asthma or COPD when evidence-based recommendations were applied. Despite efforts made to obtain detailed information from chart reviews, patient interviews, medication record reviews, standardized assessment tools and additional testing (e.g., pulmonary function tests and methacholine challenge tests), a confirmatory diagnosis was elusive in an important proportion of patients (19\%).

Our results are comparable to previous reports that used different means for participant recruitment. A multicentre study conducted in Italy (involving 24 pulmonary or geriatric institutions) investigated to what extent COPD was misdiagnosed in older patients with asthma. ${ }^{8}$ Among the 128 patients with asthma included in this study, COPD had been improperly diagnosed in $19.5 \%$, whereas $27.3 \%$ of these patients had not been diagnosed previously. Older age and greater degree of disability were factors strongly associated with misdiagnosis.

A survey conducted in North America evaluated the sex bias associated with diagnosis of COPD ${ }^{23} \mathrm{~A}$ random sample of 192 primary care providers (96 American and 96 Canadian) underwent a structured interview after being presented a hypothetical clinical case (with 6 versions differing only in the sex and age of the patients). In this study, following an initial diagnosis without spirometry, the likelihood of diagnosis of COPD increased after conducting spirometry and after receiving a corticosteroid trial for both men $(58 \% \mathrm{v}$. $74 \%$ v. $85 \%)$ and women ( $42 \%$ v. $66 \%$ v. $79 \%)$. The study showed that only $22 \%$ of physicians would have requested spirometry at presentation by patients with symptoms consistent with COPD.

Another study conducted in Scotland and the United States compared prior diagnoses of asthma and COPD with study diagnosis based on spirometric results. ${ }^{24}$ This study found that among participants with spirometry-based diagnosis of COPD, $52 \%$ reported prior diagnosis of asthma without concurrent chronic bronchitis or emphysema diagnosis, $38 \%$ reported prior diagnosis of chronic bronchitis or emphysema, and $11 \%$ reported no prior diagnosis of COPD.

Similarly, a study carried out in 2 provinces in Canada evaluated primary care practice in patients with COPD compared with recommended care..$^{25}$ Among the 1090 patients recruited by the participating physicians, spirometric confirmation of 


\begin{tabular}{|c|c|c|c|}
\hline \multirow[b]{2}{*}{ Medication } & \multicolumn{3}{|c|}{ No. $(\%)$ of patients } \\
\hline & $\begin{array}{c}\text { Previous diagnosis of } \\
\text { asthma } \\
n=181 \dagger\end{array}$ & $\begin{array}{c}\text { Previous diagnosis of } \\
\text { COPD } \\
n=34 \dagger\end{array}$ & $\begin{array}{c}\text { No previous diagnosis of } \\
\text { asthma or COPD } \\
n=127\end{array}$ \\
\hline Short-acting $\beta$-agonist & $141(77.9)$ & $22(64.7)$ & $83(65.4)$ \\
\hline Inhaled corticosteroid & $45(24.9)$ & $3(8.8)$ & $38(29.9)$ \\
\hline Inhaled corticosteroid-long-acting $\beta$-agonist & $120(66.3)$ & $30(88.2)$ & $54(42.5)$ \\
\hline Oral corticosteroid & $6(3.3)$ & $2(5.9)$ & $5(3.9)$ \\
\hline Long-acting anticholinergic & $7(3.9)$ & $13(38.2)$ & $7(5.5)$ \\
\hline Short-acting anticholinergic & $5(2.8)$ & $2(5.9)$ & $6(4.7)$ \\
\hline Theophylline & $4(2.2)$ & $1(2.9)$ & $1(0.8)$ \\
\hline Leukotriene antagonist & $20(11.0)$ & $2(5.9)$ & $5(3.9)$ \\
\hline
\end{tabular}

Table 4: Adjudicated diagnoses by expert physician panel for patients with shortness of breath referred by pharmacists

\begin{tabular}{|c|c|}
\hline Diagnosis by expert physician panel & $\begin{array}{c}\text { No. }(\%) \text { of } \\
\text { patients } \\
n=328\end{array}$ \\
\hline Asthma* & $149(45.4)$ \\
\hline Definite diagnoses & $147 / 149(98.7)$ \\
\hline Probable diagnoses & 2/149 (1.3) \\
\hline $\mathrm{COPD}^{*}$ & $97(29.6)$ \\
\hline Definite diagnoses & 94/97 (96.9) \\
\hline Probable diagnoses & $3 / 97(3.1)$ \\
\hline Other & $20(6.1)$ \\
\hline Heart failure & $9 / 20(45.0)$ \\
\hline $\begin{array}{l}\text { Restrictive lung diseases or pulmonary } \\
\text { hypertension }\end{array}$ & $8 / 20(40.0)$ \\
\hline Bronchitis & 2/20 (10.0) \\
\hline Obesity & $1 / 20(5.0)$ \\
\hline $\begin{array}{l}\text { Unknown origin (indeterminate cause for } \\
\text { SOB) }\end{array}$ & $62(18.9)$ \\
\hline \multicolumn{2}{|c|}{$\begin{array}{l}\text { Note: } \mathrm{COPD}=\text { chronic obstructive pulmonary disease, } \mathrm{SOB}=\text { shortness of } \\
\text { breath. } \\
{ }^{*} \mathrm{~A} \text { total of } 11 \text { patients had both asthma and COPD diagnoses. }\end{array}$} \\
\hline
\end{tabular}

diagnosis was reported by only $56 \%$ of them. In addition, pharmacological treatment matching guideline recommendations was identified in only a third of the study population.

A more recent study conducted in Italy assessed the level of asthma misdiagnosis among patients reporting respiratory symptoms to their general practitioner and undergoing treatment with inhaled corticosteroids. ${ }^{9}$ From a total of 2090 patients registered in general practitioners' databases as receiving at least 3 prescriptions of inhaled or nebulized corti- costeroids during the 12 months preceding the start of the study, only $47 \%$ were diagnosed with asthma.

Finally, a study conducted in 10 Canadian cities used random digital dialing to recruit adults who reported a history of previous physician-diagnosed asthma within the past 5 years to determine whether a current diagnosis of asthma could be ruled out and asthma medications safely stopped. ${ }^{10}$ Asthma was ruled out in $33 \%$ of 613 participants who underwent home peak flow and symptom monitoring, spirometry and serial bronchial challenge tests. Those participants in whom asthma was ruled out were less likely to have undergone testing for airflow limitation in the community at the time of diagnosis when compared with those in whom asthma diagnosis was confirmed (43.8\% v. $55.6 \%$, respectively).

The findings of these studies and the current study suggest that misdiagnosis in community-dwelling patients led to exposure to unnecessary and expensive treatments and, likely, to undesired health outcomes and delayed diagnosis. Importantly, misdiagnosis could also compromise the validity of research studies based on pharmacy dispensations (e.g., pharmacoepidemiology studies that often use 2 dispensations of $\beta$-agonists as a proxy for a diagnosis of asthma). In addition, the poor agreement between previous diagnoses by primary care providers and by our expert physician panel could have an important clinical impact on patients' outcomes when they are exposed to chronic and inappropriate therapies. Educational efforts should be directed to improve the diagnostic approaches of primary care providers and other health practitioners. Moreover, the results suggest that other health professionals, such as pharmacists, should be empowered to direct patients toward optimal diagnosis and management.

\section{Limitations}

Our sample of 475 represents eligible patients. Unfortunately, we were not able to document the total number of 
Table 5: Agreement between diagnoses of asthma and chronic obstructive pulmonary disease by primary care providers and those derived from pulmonary function testing

\begin{tabular}{|c|c|c|c|c|c|c|c|}
\hline & & \multicolumn{6}{|c|}{ PFT-derived diagnoses } \\
\hline & & \multicolumn{3}{|c|}{ Asthma* } & \multicolumn{3}{|c|}{ COPD* } \\
\hline & & Yes & No & Total & Yes & No & Total \\
\hline \multirow{7}{*}{$\begin{array}{l}\text { Prior diagnosis } \\
\text { of OAD by } \\
\text { PCP }\end{array}$} & Yes & 106 & 87 & 193 & 27 & 11 & 38 \\
\hline & No & 43 & 92 & 135 & 70 & 220 & 290 \\
\hline & Total & 149 & 179 & 328 & 97 & 231 & 328 \\
\hline & PPV, \% & & 54.9 & & & 71.1 & \\
\hline & NPV, \% & & 68.1 & & & 75.9 & \\
\hline & $\kappa$ value & & 0.22 & & & 0.28 & \\
\hline & $p$ value & & $<0.001$ & & & $<0.001$ & \\
\hline
\end{tabular}

patients from which these patients with shortness of breath were screened.

One of the main strengths of our study is the use of standardized diagnostic approaches following the recommendations from international guidelines by an outcome adjudication panel of experts. We collected robust new information, and previous diagnostic tests were available for all but $16 \%$ of the study population. Despite these details, there was a substantial proportion of patients (19\%) for whom expert clinicians, using accepted standards and protocols, could not provide a diagnosis. This implies that a considerable number of patients are receiving medication for chronic respiratory conditions based on non-evidence-based medical practice; there is variability of airway responsiveness measurements in diseases like asthma; and the accuracy of our estimates could be affected by the completeness of the information available for assessment. Although we did not explore in detail potential sources for diagnostic opportunity bias, we acknowledge that variation in the quality of medical reporting could be an important source of nondifferential bias in our study.

Although the recruitment of community-dwelling patients through volunteering community pharmacists minimizes the selection bias introduced by physician diagnosis and random digit dialing used in previous studies, some cases may have reflected the pharmacist's clinical concern for confirmation of diagnosis. Our study excluded patients who could not communicate in English, were pregnant or were unable to attend the study appointments. The participating pharmacists may not be representative, given that they volunteered to participate; however, that should not have biased the patient sample. Importantly, many patients with shortness of breath may be untreated; therefore, patients with mild obstructive airway disorders are underrepresented in our study.

Despite multiple efforts to facilitate participants' attendance to the pulmonary function tests laboratory, 147 (about $30 \%$ ) participants did not present to the laboratory and were considered lost to follow-up. There were no baseline charac- teristics for these patients to evaluate the difference with those who attended pulmonary function testing, and therefore the distribution of obstructive airway disorders in these participants could have been different.

\section{Conclusion}

We found that less than half of community-dwelling patients receiving treatment with inhaled medications for shortness of breath and presumed obstructive airway disorders had confirmed asthma, about a quarter had COPD and a quarter had no demonstrable obstructive airway disorders. These findings, coupled with the fact that only about $40 \%$ of participants had ever had pulmonary function tests performed, highlights the need to avoid empiric treatment with $\beta$-agonists and inhaled corticosteroid agents, increase the use of objective measures of lung function for the diagnosis of obstructive airway disorders, and identify factors associated with patient misdiagnosis.

\section{References}

1. Dyspnea - 27. Ottawa: Medical Council of Canada. Available: https://mcc.ca/ objectives/expert/key/27/?cn-reloaded=1 (accessed 2020 Sept. 14).

2. Rowe BH, Voaklander DC, Marrie TJ, et al. Outcomes following chronic obstructive pulmonary disease presentations to emergency departments in Alberta: a population-based study. Can Respir 7 2010;17:295-300.

3. McKenna P, MacLeod K, Le C, et al. Management of acute exacerbation of COPD in rural Alberta emergency departments. Can 7 Rural Med 2015;20: $7-14$.

4. Global strategy for the diagnosis, management and prevention of chronic obstructive pulmonary disease, 2016. Fontana (WI): The Global Initiative for Chronic Obstructive Lung Disease (GOLD); 2016. Available: https://goldcopd. org (accessed 2019 Aug. 6).

5. Global Strategy for Asthma Management and Prevention, 2017. Fontana (WI): Global Initiative for Asthma; 2017. Available: https://ginasthma.org (accessed 2019 Aug. 6).

6. Tsuyuki RT, Sin DD, Sharpe HM, et al. Management of asthma among community-based primary care physicians. F Asthma 2005;42:163-7.

7. Abramson MJ, Schattner RL, Sulaiman ND, et al. Accuracy of asthma and COPD diagnosis in Australian general practice: a mixed methods study. Prim Care Respir 7 2012;21:167-73.

8. Bellia V, Battaglia S, Catalano F, et al. Aging and disability affect misdiagnosis of COPD in elderly asthmatics: the SARA study. Chest 2003;123:1066-72.

9. Magnoni MS, Caminati M, Senna G, et al. Asthma under/misdiagnosis in primary care setting: an observational community-based study in Italy. Clin Mol Allergy 2015;13:26. 
10. Aaron SD, Vandemheen KL, FitzGerald JM, et al. Reevaluation of diagnosis in adults with physician-diagnosed asthma. 7AMA 2017;317:269-79.

11. Gershon AS, Hwee J, Chapman KR, et al. Factors associated with undiagnosed and overdiagnosed COPD. Eur Respir 7 2016;48:561-4.

12. Diab N, Gershon AS, Sin DD, et al. Underdiagnosis and overdiagnosis of chronic obstructive pulmonary disease. Am 7 Respir Crit Care Med 2018; 198:1130-9

13. Gershon AS, Thiruchelvam D, Chapman KR, et al. Health services burden of undiagnosed and overdiagnosed COPD. Chest 2018;153:1336-46.

14. Richter CA, Kalenga JC, Rowe BH, et al. Practice patterns and outcomes in patients presenting to the emergency department with acute heart failure. Can 7 Cardiol 2009;25:e173-8.

15. Jones PW, Harding G, Berry P, et al. Development and first validation of the COPD Assessment Test. Eur Respir 7 2009;34:648-54.

16. Juniper EF, O'Byrne PM, Guyatt GH, et al. Development and validation of a questionnaire to measure asthma control. Eur Respir 7 1999;14:902-7.

17. Fletcher CM, Elmes PC, Fairbairn AS, et al. The significance of respiratory symptoms and the diagnosis of chronic bronchitis in a working population. $B M \mathcal{F} 1959 ; 2: 257-66$

18. White PDMM. The classification of cardiac diagnosis. FAMA 1921;77:1414-5.

19. Miller MR, Crapo R, Hankinson J, et al. General considerations for lung function testing. Eur Respir 7 2005;26:153-61.

20. Culver BH, Graham BL, Coates AL, et al. Recommendations for a standardized pulmonary function report. An official American Thoracic Society technical statement. Am 7 Respir Crit Care Med 2017;196:1463-72.

21. Cockcroft DW, Davis BE, Todd DC, et al. Methacholine challenge: comparison of two methods. Chest 2005;127:839-44.

22. Arnold JM, Liu P, Demers C, et al. Canadian Cardiovascular Society consensus conference recommendations on heart failure 2006: diagnosis and management. Can 7 Cardiol 2006;22:23-45.

23. Chapman KR, Tashkin DP, Pye DJ. Gender bias in the diagnosis of COPD. Chest 2001;119:1691-5

24. Tinkelman DG, Price DB, Nordyke RJ, et al. Misdiagnosis of COPD and asthma in primary care patients 40 years of age and over. 7 Asthma 2006; 43:75-80.

25. Bourbeau J, Sebaldt RJ, Day A, et al. Practice patterns in the management of chronic obstructive pulmonary disease in primary practice: the CAGE study. Can Respir 7 2008;15:13-9.

Competing interests: Ross Tsuyuki has received investigator-initiated funds from Merck, and consulting fees from Emergent BioSolutions and Shoppers Drug Mart. Darcy Marciniuk reports funding from the Canadian Respiratory Research Network, the Canadian Institutes of Health Research (CIHR), the Respiratory Health Network of the Fonds de la recherche en santé du Québec, Almirall, Merck, Nycomed, Pfizer Canada, the Canadian Thoracic Society and Theratechnologies; nonfinancial support from GlaxoSmithKline; grants and personal fees from AstraZeneca, Boehringer Ingelheim, GlaxoSmithKline, Novartis and the Lung Association of Saskatchewan; personal fees from the Canadian Foundation for Healthcare Improvement, the Chinese Committee of Health and Family Planning, Health Canada, Mylan, the Saskatchewan Ministry of Health, the Saskatchewan Health Authority, and Yukon Health and Social Services; and grants from Canada Health Infoway, CIHR, the Lung Health Institute of Canada, Sanofi, Saskatchewan Health Research Foundation and Schering-Plough. No other competing interests were declared.

Affiliations: Department of Emergency Medicine (Villa-Roel, Rowe), Department of Medicine (Tsuyuki, Mayers, Vethanayagam, Chan, Rowe), School of Public Health (Rowe), Department of Pharmacology (Tsuyuki), University of Alberta, Edmonton, Alta.; Division of Community Health and Humanities (Midodzi), Memorial University, St. John's, NL; Department of Medicine (Marciniuk), University of Saskatchewan, Saskatoon, Sask.

Contributors: All of the authors contributed to the conception and design of the work, and the acquisition, analysis and interpretation of data. All of the authors drafted the manuscript, revised it critically for important intellectual content, gave final approval of the version to be published and agreed to be accountable for all aspects of the work.

Funding: The authors acknowledge the funding of the Alberta Strategy to Help Manage Asthma (ASTHMA) study, funded at arm's length by Merck Canada.

Data sharing: Data can be made available on request to the corresponding author.

Acknowledgement: During this study, Brian Rowe was supported by a Tier I Canada Research Chair in Evidence-based Emergency Medicine from the Government of Canada through the Canadian Institutes of Health Research.

Supplemental information: For reviewer comments and the original submission of this manuscript, please see www.cmajopen.ca/content/8/3/ E605/suppl/DC1. 